\title{
Primacy in animals' working memory: Artifacts
}

\author{
E. A. GAFFAN \\ University of Reading, Reading, England
}

\begin{abstract}
In response to commentaries on an earlier review (Gaffan, 1992), it is acknowledged that there is more recent evidence for primacy in animals' list memory, which is not susceptible to the methodological criticisms discussed in the review. However, methods advocated by the commentators are liable to produce spurious assessments of primacy, and the original objections still stand.
\end{abstract}

My paper (E. A. Gaffan, 1992) has been interpreted by the respondents as claiming that primacy in animal working memory is not a real phenomenon. On the contrary, I acknowledged that there was some valid evidence of primacy in animals' spatial memory, so it would hardly be surprising if it also exists in nonspatial domains. The fact remains that the methods used to demonstrate and measure primacy have often, for varying reasons and to varying degrees, failed in their purpose.

Kesner, Chiba, and Jackson-Smith (1994) argue that their practice of selecting data from the trial block in which rats attain a criterion of $6 / 8$ correct responses at first and last serial positions is not problematic, contrary to my criticisms, because (1) such selected data do not always generate lower-than-expected variance, and (2) the performance so obtained does not differ significantly from that of the same rats tested later (as unoperated controls) during a fixed number of test trials without selection on the basis of a criterion. Neither argument is convincing.

1. Lower-than-expected variance is a possible symptom of various diseases, not a disease in itself (see E. A. Gaffan, 1992, p. 250). Performances from a criterion run in which rats, by definition, attain $6 / 8(75 \%)$ correct cannot be treated as real data, whatever their variance; they misrepresent the population performance. I had assumed that this was obvious, but perhaps a numerical illustration is worthwhile.

Suppose the true population mean performance at Serial Position 1 is $65 \%$ correct. By the binomial theorem, $43 \%$ of the subjects are expected to make six or more correct choices at that position in any block of eight trials; if two such blocks are run, $67 \%$ of the subjects are expected to attain the "criterion" in at least one of the blocks. The mean score of those subjects in their "criterion block" is, trivially, at least $75 \%$ correct, exceeding the true score by more than $10 \%$.

The more the artificial mean of $75 \%$ deviates from the true mean, the more likely it is that the data in the "criterion" block is a biased subsample, with truncated variance, from the true distribution. Whether variance is com-

Address correspondence to E. A. Gaffan, Department of Psychology, University of Reading, Reading RG6 2AL, England. pressed or not, the mean is artificial. The calculations by Kesner et al. (1994) on raw data from their laboratory agree with my conclusions from their published graphs, in implying that the misrepresentation is more severe for order memory than for item memory.

Kesner et al. (1994) do not mention the data reported by Kesner and Novak (1982), which I demonstrated to suffer from lower-than-expected variance that could not be a symptom of "criterion" testing (E. A. Gaffan, 1992, pp. 248-250). I reiterate my conclusion that the report by Kesner and Novak is probably unreliable.

2. Kesner et al. (1994) combined the data from the earlier criterion run and the subsequent test with a fixed number of trials into a single analysis of variance. They found that the difference between the two sets of data was not significant, and that significant primacy was obtained when the two sets were averaged. That is irrelevant; the earlier data should never have been included in any analysis. If the second set of data on their own evince a significant serial position effect-well and good.

Wright (1994) contends that I gave too much credence to the argument that primacy effects in some studies of visual memory may be artifactual, engendered by the practice of having subjects initiate each list with an observing response. His counterargument is that, in experiments employing an observing response, subjects sometimes do and sometimes do not show primacy (e.g., as a function of varying retention interval); therefore, primacy cannot be caused by the observing response.

The logic is not persuasive. An analogous argument would be that people who are drunk sometimes behave aggressively and sometimes do not; therefore, alcohol cannot have played a part in their aggression. A more reasonable conclusion is that alcohol is not the only determinant of aggression; other factors may additionally decide whether aggression is expressed. Likewise, a listinitiation response might influence primacy, and other factors (e.g., retroactive interference caused by strong memory for the later portion of the list) might sometimes prevent that primacy from being manifested.

The only way to decide whether list initiation is a relevant factor is to manipulate the presence or absence of a list-initiation response. I acknowledge that the recent study by Castro and Larsen (1992) gives evidence for 
primacy in monkeys, which cannot have depended on an observing response. However, their use of a brief, constant intertrial interval presumably made list onset highly predictable, and the demonstration would have been even more impressive had the ITI been variable. In any event, it does nothing to elucidate whether, in the many studies that did employ an observing response, that response contributed to the magnitude of the primacy effect. It is necessary, in a single experiment, to compare performance with and without the observing response.

This was recently done by Millichap (1993) with human subjects. The procedure was based on that of Wright et al. (1990), using lists of four computer-generated kaleidoscopes. Half the lists were initiated by the subject's pressing a key, half were initiated independently, and all else was held constant as far as possible. Primacy was observed in the first condition and not in the second. Therefore, list initiation by a human subject can sometimes influence the magnitude of primacy. Whether the same is true of animals is at present unknown.

A number of recent experiments have provided demonstrations of primacy in animals that are more convincing than earlier ones, not only for visual stimuli (Castro \& Larsen, 1992) but also for spatial items (Crystal \& Shettleworth, 1994; Harper, McLean, \& Dalrymple-Alford, 1993). I agree with both Kesner et al. (1994) and Wright (1994) that animals do, under certain conditions, manifest interesting serial-position effects, including primacy, and that we should ask what those conditions are and what mechanisms are responsible (Buffalo, D. Gaffan, \& Murray, in press). However, if we are to study serial-position effects, we must measure their form and magnitude in a valid and unbiased manner. I hope that this discussion has contributed to that end.

\section{REFERENCES}

Buffalo, B., Gaffan, D., \& Murray, E. A. (in press). A primacy effect in monkeys when list position is relevant. Quarterly Journal of Experimental Psychology.

Castro, C. A., \& Larsen, T. (1992). Primacy and recency effects in nonhuman primates. Joumal of Experimental Psychology: Animal Behavior Processes, 18, 335-340.

Crystal, J. D., \& Shettleworth, S. J. (1994). Spatial list learning in black-capped chickadees. Animal Learning \& Behavior, 22, 77-83.

Gaffan, E. A. (1992). Primacy, recency, and the variability of data in studies of animals' working memory. Animal Learning \& Behavior, 20, 240-252.

Harper, D. N., Mclean, A. P., \& Dalrymple-Alford, J. C. (1993). List item memory in rats: Effects of delay and delay task. Journal of Experimental Psychology: Animal Behavior Processes, 19, 307-316.

Kesner, R. P., Chiba, A. A., \& JACKson-Smith, P. (1994). Rats do show primacy and recency effects in memory for lists of spatial locations: A reply to Gaffan. Animal Learning \& Behavior, 22, 214-218.

Kesner, R. P., \& Novak, J. M. (1982). Serial position curve in rats: Role of the dorsal hippocampus. Science, 218, 173-175.

Millichap, A. J. (1993). The primacy effect in recognition memory for serial lists of visual stimuli. Unpublished bachelor's thesis, University of Reading, Reading, England.

Wright, A. A. (1994). Primacy effects in animal memory and human nonverbal memory. Animal Learning \& Behavior, 22, 219-223.

Wright, A. A., Cook, R. G., Rivera, J. J., Shyan, M. R., NeIworth, J. J., \& JiTsumori, M. (1990). Naming, rehearsal and interstimulus interval effects in memory processing. Journal of Experimental Psychology: Learning, Memory, \& Cognition, 15, 1043-1059.

(Manuscript received January 12, 1994; revision accepted for publication January 19,1994 .) 